\title{
Quantitation of Aflatoxins in Food Materials Using HPLC-FLD Method
}

\author{
Fevzi Kilicel", Hacer Sibel Karapinar, Aysel Cimen \\ Faculty of Science, Department of Chemistry, Karamanoglu Mehmetbey University, Karaman, Turkey

\section{Email address:} \\ fevzi@kmu.edu.tr (F. Kilicel), sibelkarapinar@hotmail.com (H. S. Karapinar), ayselcimen42@hotmail.com (A. Cimen) \\ ${ }^{*}$ Corresponding author
}

\section{To cite this article:}

Fevzi Kilicel, Hacer Sibel Karapinar, Aysel Cimen. Quantitation of Aflatoxins in Food Materials Using HPLC-FLD Method. Science Journal of Analytical Chemistry. Vol. 5, No. 6, 2017, pp. 90-97. doi: 10.11648/j.sjac.20170506.11

Received: April 4, 2017; Accepted: April 22, 2017; Published: November 14, 2017

\begin{abstract}
In this study, a sensitive high performance liquid chromatography coupled to a fluorescence detector (HPLCFLD) method after post-column derivatisation was applied for the presence of aflatoxins (AFs) in 45 samples (dried apricots, raisins, dried figs, nuts, peanuts, almonds, corn, redpepper, blackpepper, bread and moldy cheese). Samples were collected four seasons from several open market places in Karaman/Turkey and checked for AFs levels. At the same time bread samples were incubated for seven day outdoors. The purpose of this experiment is to determine the time required to reach the critical aflatoxin amounts in the bread that we consumed in our home. AFs were present in $75 \%$ of dried apricots $(6 / 8)$, 100\% of raisins $(8 / 8), 100 \%$ of dried figs $(8 / 8), 75 \%$ of nuts $(6 / 8), 50 \%$ of peanuts $(4 / 8), 50 \%$ of almonds $(4 / 8), 100 \%$ of corn $(8 / 8)$, $100 \%$ of blackpepper (8/8), $100 \%$ of redpepper (8/8), $78.5 \%$ of bread (11/14), $75 \%$ of moldy cheese (3/4) at total AF levels ranging. Eight redpepper samples were above the European maximum tolerable limit (MTL) of $8 \mu \mathrm{g} \mathrm{kg}^{-1}$ for AFB1, while total AFs concentration exceeded the MTL of $10 \mu \mathrm{g} \mathrm{kg}^{-1}$ in eight redpepper samples. The amount of aflatoxin in other samples is lower than the value of European MLT.
\end{abstract}

Keywords: Aflatoxins, HPLC-FLD, Food Material, Derivatization, Turkey

\section{Introduction}

Aflatoxins (AFs) consist of a group of approximately 20 related fungal metabolities, although only aflatoxins B1 (AFB1), B2 (AFB2), G1 (AFG1), G2 (AFG2) are normally found in foods. Aflatoxins $B 2$ and $G 2$ are the hydro derivatives of the parent compounds. They are major class of mycotoxins produced by at least three species of Aspergillus, Aflatoxins flavus, Aflatoxins parasiticus and Aflatoxins nomiusand can occur in wide range of important raw food commodities, including cereals, nuts, spices, figs and dried fruit. The "B" and "G" refer to the blue and green fluorescent colours produced by these compounds under UV light on thin-layer chromatography plates, while the subscript numbers 1 and 2 indicate major and minor compounds, respectively [1]. Aflatoxinsflavus is more adapted to the aerial parts of plants (leaves, flowers, and fruits) and produces only B AFs, while Aflatoxins parasiticus produces both B and G AFs is well adapted to a soil environment [2]. AFs have been associated with several toxic effects in animal and human health including carcinogenic, mutagenic, teratogenic and immunosuppressive activity [3]. AFB1 is the most potent genotoxic and carcinogenic AFs and among the most commonly found in agricultural products [1]. Furthermore, the International Agency for Research on Cancer (IARC) acknowledges that there is sufficient evidence in humans for the carcinogenicity of naturally occurring AFB1 and mixtures of AFs [4], with a role in the aetiology of liver cancer, notably among subjects who are carries of hepatitis B virus surface antigens [5]. AFs are most likely to contaminate maize and maize products, cottonseed, spices, figs and other dried fruits, groundnuts and tree nuts such as Brazil nuts, pecans, pistachio nuts and walnuts.

The groundnut, which belongs to the family Fabaceae is also a very popular fruit throughout the world due to its high nutrition value and taste [6]. China is the largest producer of groundnut in the world with 16.1 million metric tonnes (about $44.7 \%$ of world production), followed by India $(19.3 \%)$, Nigeria (8.2\%) and United States (4.6\%) [7]. Turkey is the leading producer of peanuts in Europe and associated countries 
with almost 80000 metric tonnes. The peanuts is used not only as raw, roasted and salted but also for a variety of applications including peanuts oil, peanuts butter, peanuts flour as well as many other uses. Peanuts have also been reported to be sensitive to AFs contamination in the field conditions before harvest, during post-harvest drying and curing, and in storage and transportation. The European Union has set maximum levels for certain contaminants in foodstuffs according to Commission Regulation (EC) No 1881/2006 [8], which has been amended and replaced with new regulations to revise legal limits for aflatoxins in food stuffs. The EU Commission established maximum tolerable limits (MTL) of $8 \mu \mathrm{g} \mathrm{kg}^{-1}$ for AFB1 and $10 \mu \mathrm{g} \mathrm{kg}^{-1}$ for the sum of AFB1, AFB2, AFG1 and AFG2 in almonds, pistachios and apricot kernels, intended for direct human consumption or use as ingredient in foodstuffs. However, the MTL of 2 and $4 \mu \mathrm{g} \mathrm{kg}^{-1}$ for AFB1 and total AFs, respectively for groundnuts and other oilseeds and processed products have been set by EU [9].

The aim of this study was to display dried apricots, raisins, dried figs, nuts, peanuts, almonds, corn, redpepper, blackpepper, bread and moldy cheese to collected from Karaman/Turkey for their AFs presence and to quantitate their respective levels using a sensitive HPLC-FLD method after post-column derivatisation.

\section{Materials and Methods}

\subsection{Chemicals and Reagents}

Sodium chloride, nitric acid and potassium bromide were provided from Merck (Merck Darmstadt Co.). Acetonitrile and methanol (both of HPLC grade) were supplied by Sigma Aldrich. All aqueous solutions were prepared with ultra pure distilled water obtained from a water purification system (Millipore Milli-Q Plus). The IACs AflaPrep were purchased from R-Biopharm Rhone. The mixed standards of AFB1, AFB2, AFG1 and AFG2 were supplied by R-Biopharm Rhone. The mixture in each bottle consists of $0.25 \mu \mathrm{g}$ AFB1, $0.25 \mu \mathrm{g}$ AFB2, $0.25 \mu \mathrm{g}$ AFG1 and $0.25 \mu \mathrm{g}$ AFG2 in one mililitre of methanol.

\subsection{Apparatus}

A Waring blender with a 1-L container, operating at high speed (Waring Products Co., Connecticut, USA) and a vacuum manifold (Agilent Technologies, Santa Clara, CA, USA), which is capable of processing 20 samples simultaneously were used. HPLC analysis was performed using an Agilent 1100 series HPLC system consisted of a G1310A isocratic pump, a G1379A degasser, a G1313A autosampler, a G1316A column oven and a fluorescence detector model G1321A (Agilent Technologies, Palo Alto, California). Chemstation 3D software was used to control the system and the process signals. Chromatographic separations of AFs were achieved with a silica $5 \mu \mathrm{m} \mathrm{ACE} 5 \mathrm{C} 18,100^{\circ} \mathrm{A}$, 25 x $4.6 \mathrm{~mm}$ column supplied by Advanced Chromatography Technologies. Postcolumn derivatisation was carried out with electrochemically generated bromine in Cobra cell using a reaction tube of $340 \times 0.5 \mathrm{~mm}$ i.d. PTFE to enhance the fluorescence intensity of AFB1 and AFG1.

\subsection{Samples}

A total of 45 samples were analysed for AFs. The samples (dried apricots, raisins, driedfigs, nuts, peanuts, almonds, corn, redpepper, blackpepper, bread and moldy cheese) were collected four seasons from Karaman/Turkey and checked for AFs levels. At the same time bread samples were incubated for seven day outdoors. Representative portion of a minimum of $100 \mathrm{~g}$ of sample was taken and transported to the laboratory in an insulated container. All samples were ground with waring blender to produce a homogeneous particle size and stored in a glass container in a refrigerator until analysis.

\subsection{Standard Solution Preparation}

Stock solution of aflatoxin standard mix was diluted with methanol to obtain concentration of $10 \mathrm{ng} \mathrm{mL}^{-1}$ for AFB1, AFB2, AFG1 and AFG2. From this intermediate solution, a series of working standards from $0.025,0.0625,0.125,0.25$ and $0.5 \mathrm{ng} \mathrm{mL}^{-1}$ for AFG1 and AFB2 and 0.1, 0.250, 0.5, 1 . and $2.0 \mathrm{ng} \mathrm{mL}{ }^{-1}$ for AFG1 and AFB1 were prepared freshly in LC mobile phase consisting of water-eacetonitrilemethanol $(560+180+260)(\mathrm{v}+\mathrm{v}+\mathrm{v})$.

\subsection{Extraction and Clean-up}

The AOAC Official Method 999.31 [10] was used to detect AFs in pistachio and groundnut samples. This method involves methanol-water extraction, IAC cleanup and liquid chromatography coupled with fluorescence detector after post column derivatisation. Briefly, $25 \mathrm{~g}$ of finely-ground subsample was blended with $125 \mathrm{~mL}$ methanol-water (70:30, $\mathrm{v} / \mathrm{v}$ ) and $5 \mathrm{~g} \mathrm{NaCl}$ using a waring blender at high speed for 2 min, and filtered using a prefolded filter paper. A $15 \mathrm{ml}$ aliquot of filtrate was diluted with $30 \mathrm{ml}$ water, shaken vigorously and filtered through glass microfiber filter (Wicam). Then, a $15 \mathrm{~mL}$ of diluted filtrate was passed through an AflaPrep attached onto a vacuum manifold at a flow rate of about $1 \mathrm{ml}$ per min. The column was washed twice with $10 \mathrm{~mL}$ of ultrapure water and dried with air. AFs bound to the specific antibody were eluted by passing $1 \mathrm{~mL}$ methanol through the column and collected in HPLC vials. The eluate was then diluted with $1 \mathrm{~mL}$ of ultrapure water and stored at $2-8^{\circ} \mathrm{C}$ until to the HPLC analysis.

\subsection{Chromatographic Separations}

A mixture of potassium bromide (120mg), nitric acid (350 $\mu \mathrm{L})$ and water-acetonitrile-methanol $(560+180+260)(\mathrm{v}+\mathrm{v}+\mathrm{v})$

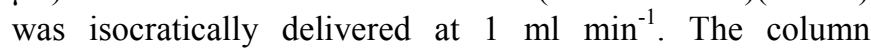
temperature was maintained at $30^{\circ} \mathrm{C}$. The injection volume into HPLC system for both Standard and sample was $100 \mu \mathrm{L}$. The fluorescence detector was set to an excitation and emission wavelengths of 360 and $435 \mathrm{~nm}$, respectively. The retention times were around 7, 8,9 and 11 min for AFG2, AFG1, AFB2 and AFB1, respectively.

Linearity, sensitivity, recovery and accuracy (precision and 
trueness) were determined to evaluate the performance of analytical method used for AFs. To assess linearity, sevenpoint calibration curves were constructed over the concentration range of $0.1-5 \mathrm{ng} \mathrm{ml}^{-1}$ for each AFs. Linear regression lines were plotted using the peak area versus the analyte concentration. The linearity was determined by linear regression analysis and expressed as coefficient of determination $\left(\mathrm{R}^{2}\right)$.

The limit of detection (LOD) and limit of quantification (LOQ) of the analytical method were calculated according to EURACHEM Guide based on data of recovery experiment [11]. Blank groundnut samples were spiked with $0.1 \mu \mathrm{g} \mathrm{kg}^{-1}$ for each analyte and measured in 10 independent replicates. The LOD and LOQ were calculated using the following relations:

$$
\mathrm{LOD}=\mathrm{X}+3 \mathrm{~s}, \mathrm{LOQ}=\mathrm{X}+10 \mathrm{~s}
$$

in which, " $\mathrm{X}$ " is the mean concentration of fortified sample blank values, and "s" is the sample standard deviation.

The recovery was calculated by the analysis of six representative samples spiked with AFB1, AFB2, AFG1 and AFG2 at two concentration levels of 0.5 and $3 \mu \mathrm{g} \mathrm{kg}^{-1}$.

The observed signal was plotted against the actual concentration. The measured concentration was determined using the obtained calibration curves and the recovery value was calculated by the following equation:

$$
\begin{gathered}
\% \text { recovery }=100 \times \text { measured concentration for spiked } \\
\text { sample/spiked }(\text { added }) \text { concentration }
\end{gathered}
$$

\section{Results and Discussion}

\subsection{Method Performance}

The analytical method was validated (in terms of linearity, sensitivity, recovery and precision and trueness) prior to the analysis of samples. Figure 1, Figure 2, Figure 3 and Figure 4 show an HPLC-FLD chromatogram of AFs in the examples $\left(\mu \mathrm{gKg}^{-1}\right)$. The linear range, linear regression equation and coefficient of determination $\left(\mathrm{R}^{2}\right)$ for each analyte are given in Table 1 . The calibration curves revealed good linearity for all analytes in related concentration ranges, with coefficient of determination greater than 0.999. Method performance characteristics for aflatoxins in samples are given in Table 2.

Table 1. Linearity data for aflatoxins.

\begin{tabular}{llll}
\hline Aflatoxins & Linearity range $\left(\boldsymbol{\mu \mathbf { g L } ^ { - 1 } )}\right.$ & Linear regression equation & $\mathbf{R}^{2}$ \\
\hline AFB1 & $0.1-5$ & $\mathrm{y}=4.96 \mathrm{x}+0.11$ & 0.9998 \\
AFB2 & $0.1-5$ & $\mathrm{y}=7.95 \mathrm{x}+0.14$ & 0.9997 \\
AFG1 & $0.1-5$ & $\mathrm{y}=2.90 \mathrm{x}+0.18$ & 0.9993 \\
AFG2 & $0.1-5$ & $\mathrm{y}=3.07 \mathrm{x}+0.13$ & 0.9996 \\
\hline
\end{tabular}

\begin{tabular}{|c|c|c|c|c|}
\hline Aflatoxins & Spiking level $\left(\mu \mathrm{gkg}^{-1}\right)$ & Mean recovery(\%) & ${ }^{\mathrm{a}} \mathrm{LOD}\left(\mu \mathrm{gkg}^{-1}\right)$ & ${ }^{\mathrm{b}} \mathrm{LOQ}\left(\mu \mathrm{gkg}^{-1}\right)$ \\
\hline AFB1 & $\begin{array}{l}0.5 \\
3\end{array}$ & $\begin{array}{l}88.14 \\
88.57\end{array}$ & 0.10 & 0.11 \\
\hline AFB2 & & $\begin{array}{l}92.23 \\
96.37\end{array}$ & 0.10 & 0.11 \\
\hline AFG1 & $\begin{array}{l}0.5 \\
3\end{array}$ & $\begin{array}{l}88.29 \\
88.28\end{array}$ & 0.11 & 0.12 \\
\hline AFG2 & $\begin{array}{l}0.5 \\
3\end{array}$ & $\begin{array}{l}96.52 \\
97.37\end{array}$ & 0.11 & 0.14 \\
\hline
\end{tabular}

$\mathrm{R}^{2}$ : Coefficient of determination.

Table 2. Method performance characteristics for aflatoxins in samples.

${ }^{\mathrm{a}}$ LOD, limit of detection of the chromatographic method.

${ }^{b}$ LOQ, limit of quantification of the chromatographic method.

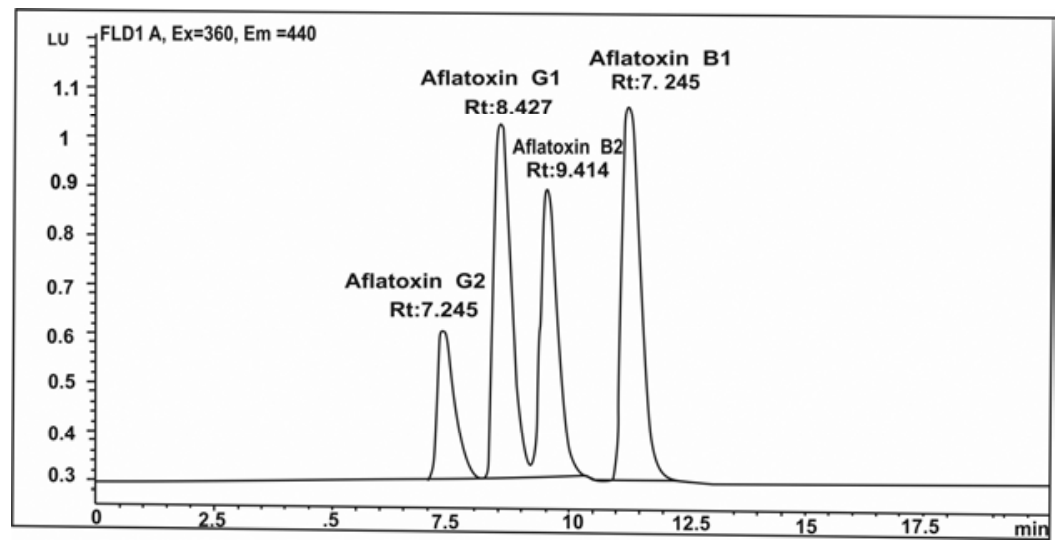

Figure 1. AFs standard solution (0.7 $\mu g L^{-1} A F B 1,0.2 \mu g L^{-1} A F B 2,0.7 \mu g L^{-1} A F G 1$ and $\left.0.2 \mu g L^{-1} A F G 2\right)$. 


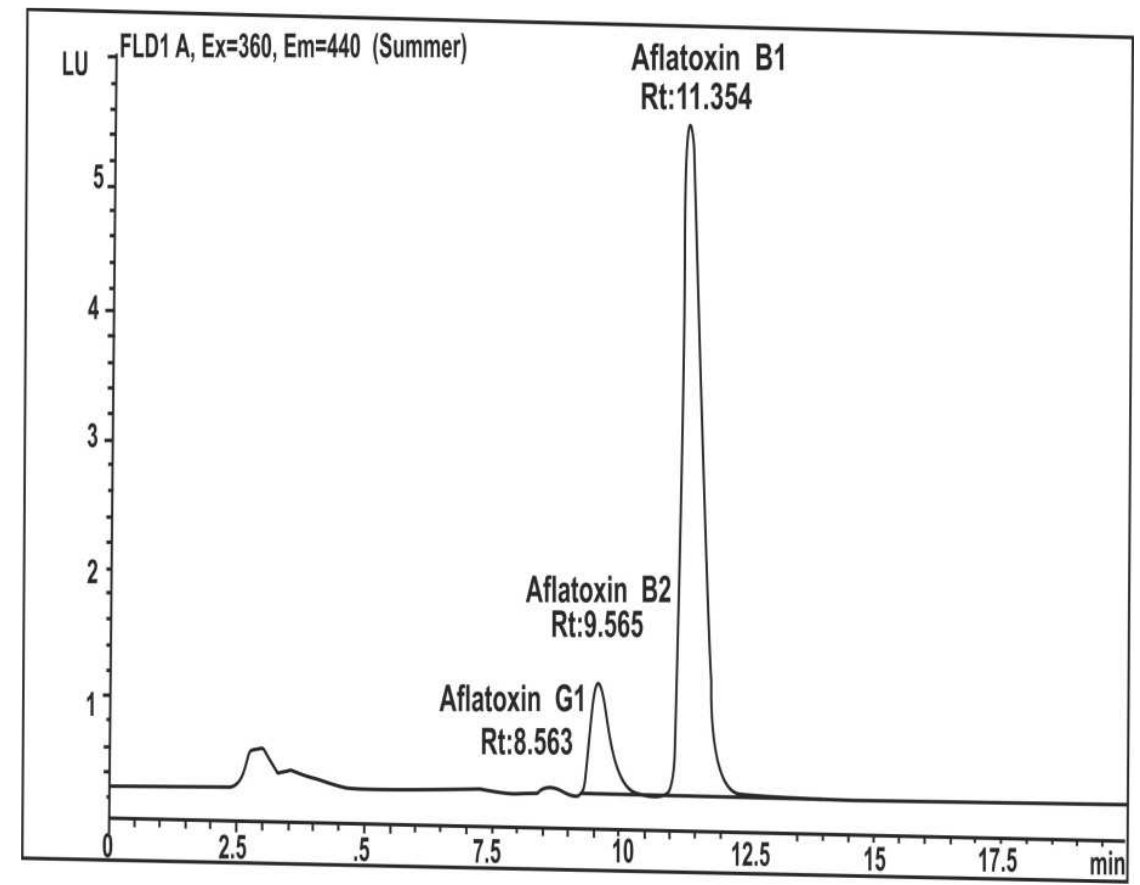

Figure 2. Naturally contaminated redpepper with $9.20 \mu \mathrm{gkg}^{-1}$ AFB1 and $0.7 \mu \mathrm{gkg}^{-1}$ AFB2 (summer).

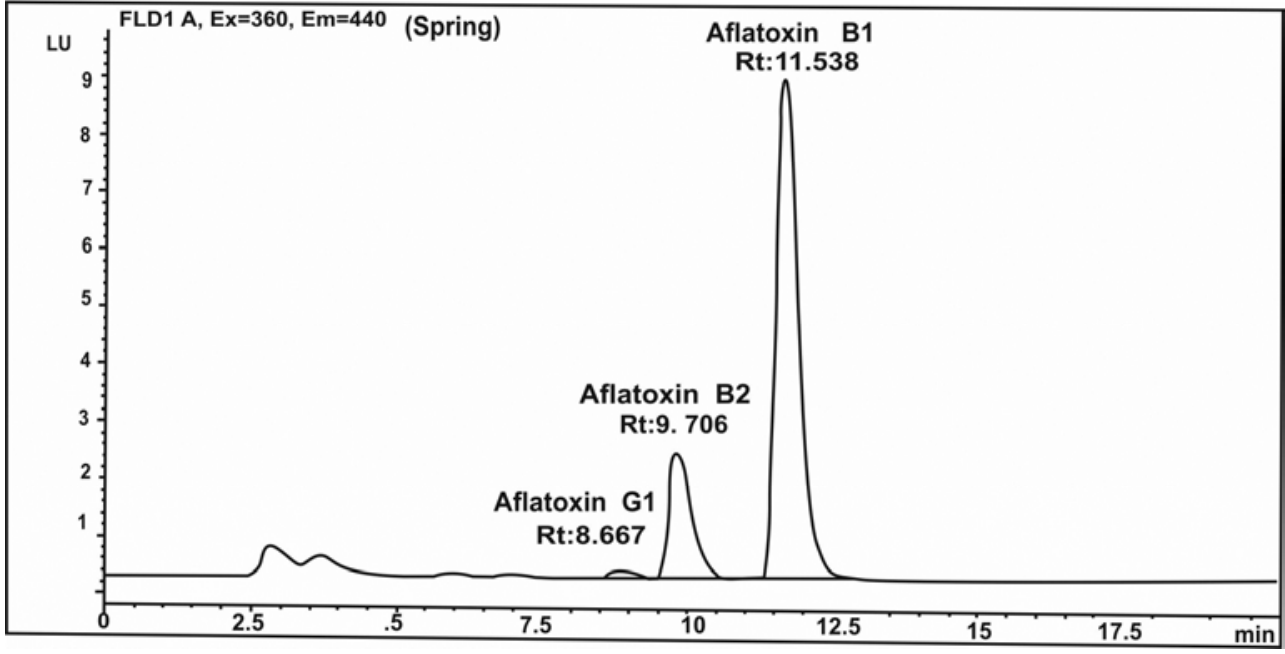

Figure 3. Naturally contaminated redpepper with $15.46 \mu \mathrm{gkg}^{-1}$ AFB1 and $1.78 \mu \mathrm{gkg}^{-1}$ AFB2 (spring).

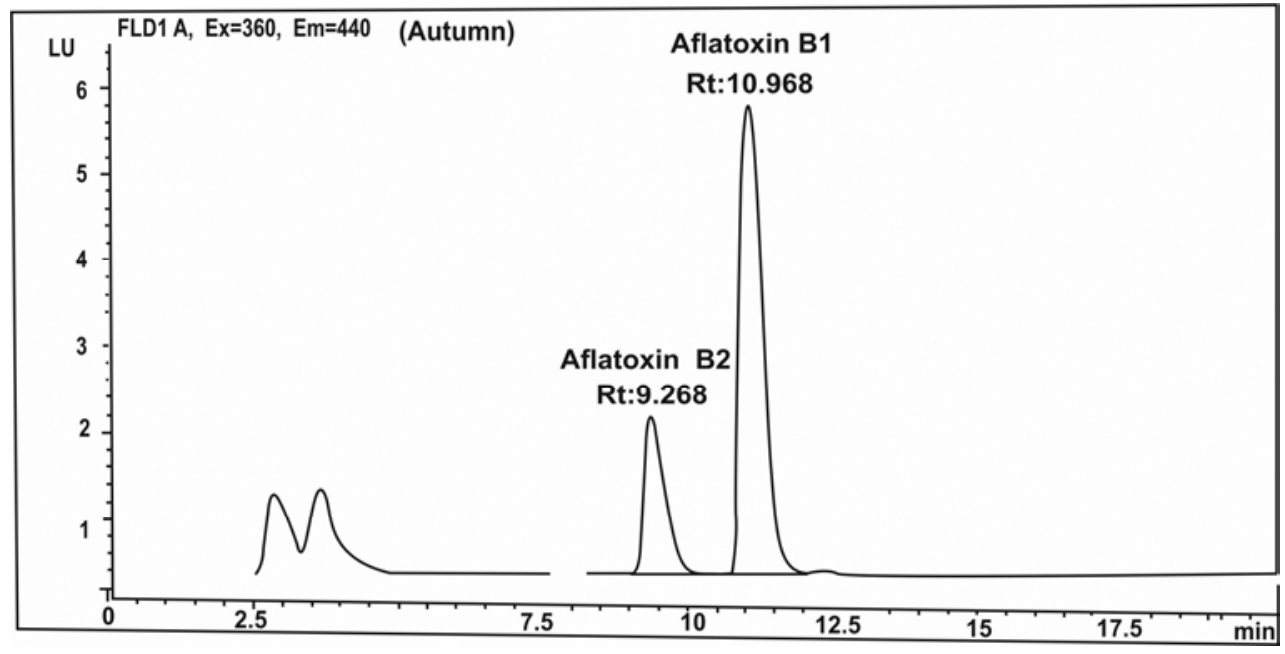

Figure 4. Naturally contaminated redpepper with $9.35 \mu \mathrm{gkg}^{-1}$ AFB1 and $1.37 \mu \mathrm{gkg}^{-1}$ AFB2 (autumn). 


\subsection{Application to Real Samples}

AFB1, AFB2, AFG1, AFG2 quantities was measured using Coring Cell derivatization device in 38 samples taken from the neighborhood market and in 7 samples taken from the market with the method of random sampling in solution prepared by the method of AOAC 991.31. The analysis results are shown in Table $3,4,5$. They indicate that only redpepper quantities (13.44 $\mu \mathrm{g}$ AFB1, $1.451 \mu \mathrm{g}$ AFB2, 0.103 $\mu \mathrm{g}$ AFG1) do not comform to the values of Europen MLT. The total amounts of aflatoxins according to the seasons are given in Table 6 . The highest amount of total aflatoxins measured for raisins, driedfigs, nuts and almonds in spring season, for corn and dried apricots in summer season, redpepper and peanut in autumn season and for red paper in winter season. The average amounts of aflatoxins measured according to the waiting time in the bread and in moldy cheese are given Table 7 . and Table 8 . respectively. They are found to be below values of the European MLT. Total aflatoxins quantities and aflatoxins B1 in samples are shown in Table 9. The aflatoxins amounts of all samples except redpepper conform to Europen values of MLT [12].

Table 3. Amounts of aflatoxins in dried apricots, raisins and dried figs $\left(\mu \mathrm{gkg}^{-1}\right),(1,2$ winter season; 3, 4 springseason ; 5, 6 summer season; 7, 8 autumn season).

\begin{tabular}{|c|c|c|c|c|c|c|c|c|c|c|c|c|}
\hline \multirow{2}{*}{$\begin{array}{l}\text { SAMPLE } \\
\text { Sample Number }\end{array}$} & \multicolumn{4}{|c|}{ DRIED APRICOTS } & \multicolumn{4}{|c|}{ RAISINS } & \multicolumn{4}{|c|}{ DRIED FIGS } \\
\hline & B1 & B2 & G1 & G2 & B1 & B2 & G1 & G2 & B1 & B2 & G1 & G2 \\
\hline 1 & --- & --- & --- & ---- & --- & --- & --- & 0.125 & --- & --- & 0.011 & --- \\
\hline 2 & --- & --- & --- & ---- & --- & --- & --- & 0.072 & --- & --- & 0.073 & --- \\
\hline 3 & 0.008 & 0.027 & 0.014 & 0.011 & --- & --- & --- & 1.426 & --- & --- & 0.093 & --- \\
\hline 4 & 0.012 & 0.004 & --- & ---- & --- & --- & --- & 1.073 & 0.001 & --- & 0.075 & --- \\
\hline 5 & --- & 0.004 & --- & ---- & --- & --- & --- & 0.445 & --- & 0.003 & 0.011 & --- \\
\hline 6 & --- & 0.006 & 0.006 & ---- & --- & --- & --- & 0.411 & --- & 0.003 & 0.018 & --- \\
\hline 7 & --- & --- & --- & 0.010 & --- & --- & --- & 0.792 & --- & --- & 0.030 & --- \\
\hline 8 & --- & --- & --- & 0.005 & --- & --- & --- & 1.029 & --- & --- & 0.037 & --- \\
\hline Mean & 0.010 & 0.010 & 0.010 & 0.009 & --- & --- & --- & 0.672 & 0.001 & 0.003 & 0.044 & --- \\
\hline SD & 0.003 & 0.011 & 0.006 & 0.003 & --- & --- & --- & 0.486 & --- & --- & 0.032 & --- \\
\hline
\end{tabular}

SD: Standart Deviation.

Table 4. Amounts of aflatoxins in nuts, peanuts and almonds ( $\left.\mu \mathrm{gkg}^{-1}\right),(1,2$ winter season; 3, 4spring season; 5, 6 summer season; 7, 8 autumn season).

\begin{tabular}{|c|c|c|c|c|c|c|c|c|c|c|c|c|}
\hline SAMPLE & NUTS & & & & PE & & & & & & & \\
\hline Sample Number & B1 & B2 & G1 & G2 & B1 & B2 & G1 & G2 & B1 & B2 & G1 & G2 \\
\hline 1 & -- & -- & -- & -- & -- & -- & -- & -- & -- & -- & -- & -- \\
\hline 2 & -- & -- & -- & -- & -- & -- & -- & -- & -- & -- & -- & -- \\
\hline 3 & 0.011 & 0.046 & -- & 0.008 & -- & -- & -- & -- & -- & 0.009 & 0.007 & 0.018 \\
\hline 4 & 0.004 & 0.020 & 0.016 & 0.024 & -- & -- & -- & 0.010 & -- & 0.001 & -- & 0.008 \\
\hline 5 & -- & 0.003 & 0.007 & 0.009 & -- & 0.001 & 0.009 & 0.012 & -- & 0.006 & 0.001 & 0.008 \\
\hline 6 & -- & 0.003 & 0.003 & 0.015 & -- & 0.006 & 0.005 & 0.008 & -- & 0.004 & -- & -- \\
\hline 7 & 0.014 & 0.001 & 0.013 & 0.018 & -- & -- & 0.004 & 0.001 & -- & -- & -- & -- \\
\hline 8 & -- & -- & 0.006 & 0.015 & -- & -- & 0.006 & 0.011 & -- & -- & 0.012 & -- \\
\hline Mean & 0.010 & 0.015 & 0.009 & 0.015 & -- & 0.004 & 0.006 & 0.008 & -- & 0.005 & 0.007 & 0.011 \\
\hline SD & 0.005 & 0.019 & 0.005 & 0.006 & -- & 0.004 & 0.002 & 0.004 & -- & 0.003 & 0.006 & 0.006 \\
\hline
\end{tabular}

SD: Standart Deviation.

Table 5. Amounts of aflatoxins in corn, black pepper and red pepper ( $\left.\mu \mathrm{gkg}^{-1}\right)$, (1, 2 winter season; 3,4 spring season ; 5,6 summer season; 7, 8 autumn season).

\begin{tabular}{|c|c|c|c|c|c|c|c|c|c|c|c|c|}
\hline \multirow{2}{*}{$\begin{array}{l}\text { SAMPLE } \\
\text { Sample Number }\end{array}$} & \multicolumn{4}{|c|}{ CORN } & \multicolumn{4}{|c|}{ BLACK PEPPER } & \multicolumn{4}{|c|}{ RED PEPPER } \\
\hline & $\mathrm{B} 1$ & B2 & G1 & G2 & $\mathrm{B} 1$ & B2 & G1 & G2 & B1 & $\mathrm{B} 2$ & G1 & G2 \\
\hline 1 & ---- & 0.002 & ---- & 0,01 & 0.011 & ---- & 0.082 & 0.028 & 21.14 & 2.040 & 0.187 & --- \\
\hline 2 & 0.001 & 0.002 & ---- & 0.019 & 0.012 & ---- & 0.105 & 0.016 & 14.35 & 1.490 & 0.137 & --- \\
\hline 3 & 0.009 & 0.008 & 0.005 & 0.010 & ---- & 0.008 & ---- & ---- & 15.46 & 1.786 & 0.018 & --- \\
\hline 4 & 0.008 & 0.008 & 0.004 & 0.007 & ---- & 0.016 & ---- & ---- & 17.20 & 1.967 & 0.180 & --- \\
\hline 5 & 0.126 & 0.052 & ---- & ---- & ---- & ---- & 0.078 & 0.016 & 9.208 & 0.701 & 0.100 & --- \\
\hline 6 & 0.128 & 0.053 & ---- & ---- & ---- & ---- & 0.040 & 0.010 & 9.598 & 0.715 & 0.089 & --- \\
\hline 8 & 2.201 & 0.117 & ---- & ---- & 0.001 & ---- & 0.028 & 0.013 & 11.17 & 1.537 & 0.061 & --- \\
\hline Mean & 0.747 & 0.047 & 0.005 & 0.012 & 0.008 & 0.012 & 0.064 & 0.017 & 13.44 & 1.451 & 0.103 & --- \\
\hline $\mathrm{SD}$ & 1.194 & 0.053 & 0.001 & 0.005 & 0.006 & 0.006 & 0.029 & 0.007 & 4.358 & 0.513 & 0.061 & --- \\
\hline
\end{tabular}

SD: Standart Deviation. 
Table 6. The total amounts of aflatoxins according to the seasons $\left(\mu \mathrm{gkg}^{-1}\right)$.

\begin{tabular}{|c|c|c|c|c|c|c|c|c|c|c|}
\hline \multirow[b]{2}{*}{ SEASONS } & \multirow[b]{2}{*}{ AF TYPE } & \multicolumn{9}{|c|}{ SAMPLE TYPE } \\
\hline & & $\begin{array}{l}\text { DRIED } \\
\text { APRICOTS }\end{array}$ & RAISINS & $\begin{array}{l}\text { DRIED } \\
\text { FIGS }\end{array}$ & NUTS & PEANUT & ALMONDS & CORN & $\begin{array}{l}\text { BLACK } \\
\text { PEPPER }\end{array}$ & $\begin{array}{l}\text { RED } \\
\text { PEPPER }\end{array}$ \\
\hline \multirow{5}{*}{ WINTER } & $\mathrm{B}_{1}$ & ---- & ---- & ---- & ---- & ---- & ---- & 0.001 & 0.012 & 17.750 \\
\hline & $\mathrm{B}_{2}$ & ---- & ---- & ---- & ---- & ---- & ---- & 0.002 & ---- & 1.765 \\
\hline & $\mathrm{G}_{1}$ & ---- & ---- & 0.042 & ---- & ---- & ---- & ---- & 0.094 & 0.162 \\
\hline & $\mathrm{G}_{2}$ & ---- & 0.100 & ---- & ---- & ---- & ---- & 0.015 & 0.022 & ---- \\
\hline & Total Aflatoxin & ---- & 0.100 & 0.042 & ---- & ---- & ---- & 0.018 & 0.127 & 19.680 \\
\hline \multirow{5}{*}{ SPRING } & $\mathrm{B}_{1}$ & 0.010 & --- & 0,001 & 0.008 & ---- & ---- & 0.009 & --- & 16.330 \\
\hline & $\mathrm{B}_{2}$ & 0.016 & ---- & ---- & 0.033 & ---- & 0.005 & 0.008 & 0.012 & 1.877 \\
\hline & $\mathrm{G}_{1}$ & 0.014 & ---- & 0.084 & 0.016 & ---- & 0.007 & 0.005 & ---- & 0.099 \\
\hline & $\mathrm{G}_{2}$ & 0.011 & 1.250 & ---- & 0.016 & 0.01 & 0.013 & 0.009 & ---- & ---- \\
\hline & Total Aflatoxin & 0.051 & 1.250 & 0.085 & 0.073 & 0.01 & 0.025 & 0.030 & 0.012 & 18.310 \\
\hline \multirow{5}{*}{ SUMMER } & $\mathrm{B}_{1}$ & ---- & ---- & ---- & ---- & ---- & ---- & 0.127 & ---- & 9.403 \\
\hline & $\mathrm{B}_{2}$ & 0.005 & ---- & 0.003 & 0.003 & 0.004 & 0.005 & 0.053 & ---- & 0.708 \\
\hline & $\mathrm{G}_{1}$ & 0.060 & ---- & 0.015 & 0.005 & 0.007 & 0.001 & ---- & 0.059 & 0.095 \\
\hline & $\mathrm{G}_{2}$ & ---- & 0.428 & ---- & 0.012 & 0.001 & 0.008 & ---- & 0.013 & ---- \\
\hline & Total Aflatoxin & 0.065 & 0.428 & 0.018 & 0,020 & 0.012 & 0.014 & 0.180 & 0.072 & 10.210 \\
\hline \multirow{5}{*}{ FALL } & $\mathrm{B}_{1}$ & ---- & ---- & ---- & 0.001 & ---- & ---- & 2.478 & 0.001 & 10,270 \\
\hline & $\mathrm{B}_{2}$ & ---- & ---- & ---- & 0.001 & ---- & ---- & 0.126 & ---- & 1.456 \\
\hline & $\mathrm{G}_{1}$ & ---- & ---- & 0.034 & 0.010 & 0.05 & 0.012 & ---- & 0.039 & 0.056 \\
\hline & $\mathrm{G}_{2}$ & 0.008 & 0.911 & ---- & 0.017 & 0.006 & ---- & ---- & 0.013 & ---- \\
\hline & Total Aflatoxin & 0.008 & 0.911 & 0.034 & 0.028 & 0.056 & 0.012 & 2.604 & 0.053 & 11.780 \\
\hline
\end{tabular}

Table 7. The mean amounts of aflatoxins according to the waiting time in the bread.

\begin{tabular}{|c|c|c|c|c|}
\hline DAYS & BREAD & & & \\
\hline & $\mathbf{B}_{1}$ & $\mathbf{B}_{2}$ & $\mathbf{G}_{1}$ & $\mathbf{G}_{2}$ \\
\hline 1. DAY & 0.003 & ---- & 0.003 & ---- \\
\hline 2. DAY & 0.006 & 0.001 & 0.013 & ---- \\
\hline 3. DAY & ---- & ---- & ---- & ---- \\
\hline 4. DAY & ---- & ---- & 0.009 & ---- \\
\hline 5. DAY & ---- & ---- & 0.016 & ---- \\
\hline 6. DAY & 0.009 & ---- & 0.009 & ---- \\
\hline 7. DAY & 0.011 & ---- & ---- & ---- \\
\hline Mean & 0.007 & 0.001 & 0.010 & ---- \\
\hline SD & 0.004 & ---- & 0.005 & ---- \\
\hline
\end{tabular}

SD: Standart Deviation.

Table 8. The mean amounts of aflatoxins in moldy cheese.

\begin{tabular}{|c|c|c|c|c|}
\hline \multicolumn{5}{|c|}{ MOLDY CHEESE } \\
\hline & $\mathbf{B}_{1}$ & $\mathbf{B}_{2}$ & $\mathbf{G}_{1}$ & $\mathbf{G}_{2}$ \\
\hline 1. Example & $\begin{array}{ll}--- \\
--\end{array}$ & $\begin{array}{ll}--- \\
---\end{array}$ & 0.046 & 0.306 \\
\hline 2. Example & ---- & --- & 0.005 & --- \\
\hline Mean & ---- & ---- & 0.025 & 0.306 \\
\hline SD & ---- & ---- & 0.029 & ---- \\
\hline
\end{tabular}

SD: Standart Deviation.

Table 9. Total aflatoxin quantities and aflatoxin B1 in samples.

\begin{tabular}{llll}
\hline SAMPLE TYPE & SAMPLE NUMBER & B1 & TOTAL AFLATOXIN(B1+B2+G1+G2) \\
\hline DRIED APRICOTS & 4 & 0.010 & 0.041 \\
RAISINS & 4 & --- & 0.672 \\
DRIED FIGS & 4 & 0.001 & 0.045 \\
NUTS & 4 & 0.004 & 0.040 \\
PEANUT & 4 & --- & 0.026 \\
ALMONDS & 4 & ---- & 0.017 \\
CORN & 4 & 0.654 & 0.708 \\
BLACK PEPPER & 4 & 0.006 & 0.066 \\
RED PEPPER & 4 & 13.440 & 14.990 \\
BREAD & 7 & 0.007 & 0.008 \\
MOLDY CHEESE & 2 & --- & 0.081 \\
\hline
\end{tabular}


According to experimental results, AFs were determined in $40(88.9 \%)$ of 45 samples. It was not determined in $5(11.1 \%)$ 45 samples. \%AFs in the examples are shown in Figure 5. Amounts of total AFs and AFB1 in dried apricots, raisins and dried figs $\left(\mu \mathrm{g} \mathrm{kg}^{-1}\right)$ are $0.01-0.041,0-0.062$ and $0.001-$ $0.045 \mu \mathrm{g} \mathrm{kg}^{-1}$ respectively (Figure 6). Amounts of total AFs and AFB1 in nuts, peanuts and almonds are found 0.004 $0.04,0-0.026$ and $0-0.017 \mu \mathrm{g} \mathrm{kg}^{-1}$ respectively (Figure 7). Amounts of total AFs and AFB1 in corn, black pepper and red pepper are found $0.654-0.708,0.006-0.066$ and $13.44-$ $14.99 \mu \mathrm{g} \mathrm{kg}^{-1}$ respectively (Figure 8). Amounts of total AFs and AFB1 in bread and boldy cheese are found $0.007-0.008$ and $0-0.081 \mu \mathrm{g} \mathrm{kg}^{-1}$ respectively (Figure 9).

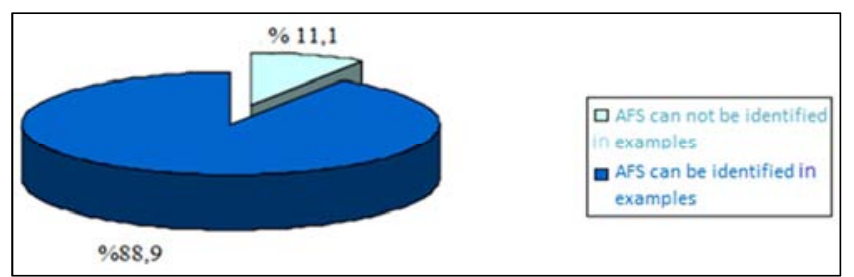

Figure 5. Amount of \% AFs can not be determined and can be determined in the samples.

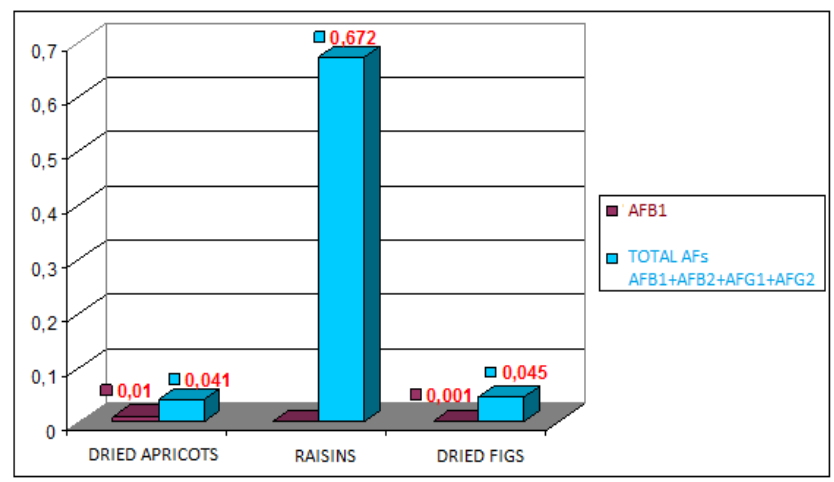

Figure 6. Amounts of total AFs and AFB1 in dried apricots, raisins and dried figs $\left(\mu \mathrm{gkg}^{-1}\right)$.

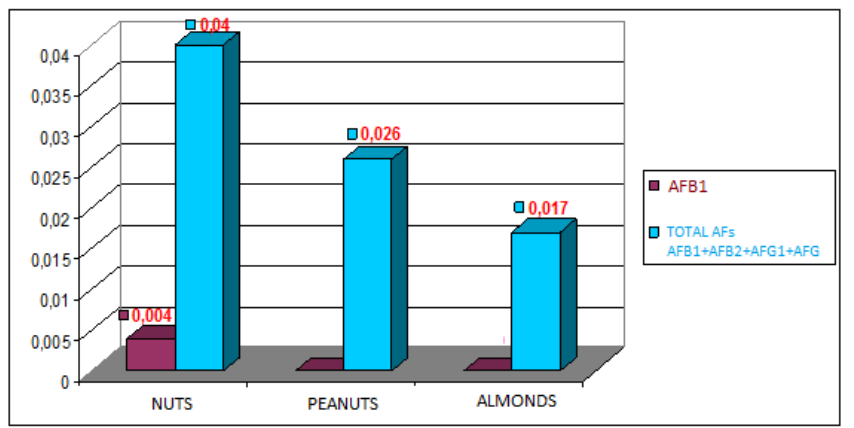

Figure 7. Amounts oftotal AFs and AFB1 in nuts, peanuts and almonds $\left(\mu g g^{-1}\right)$.

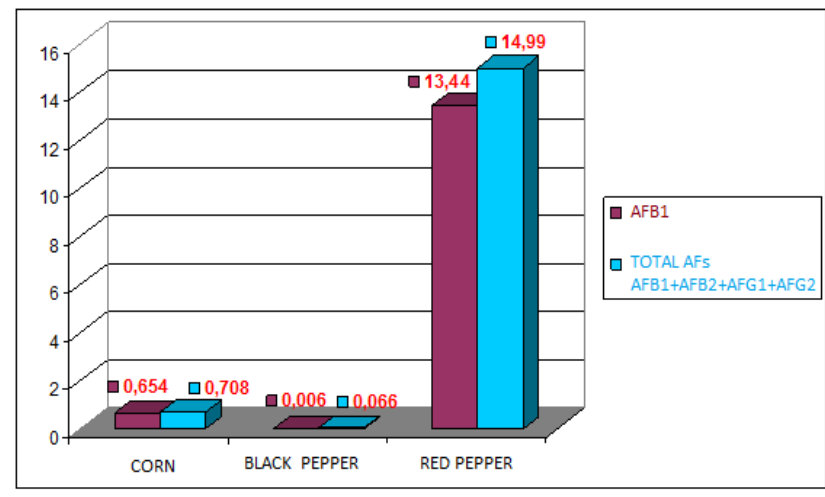

Figure 8. Amounts of total AFs and AFB1 in corn, black pepper and redpepper $\left(\mu \mathrm{gkg}^{-1}\right)$.

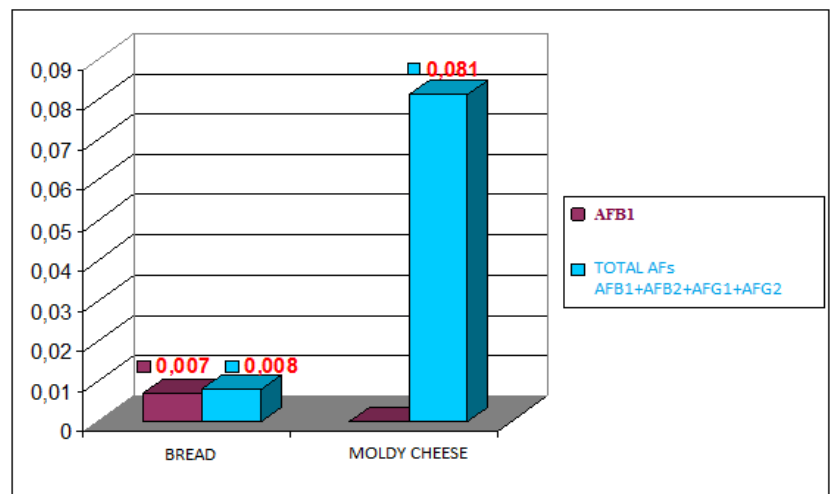

Figure 9. Amounts of total AFs and AFB1 in bread and boldy cheese $\left(\mu \mathrm{gkg}^{-1}\right)$.

Because of the health risks linked to AFs in food, it is an important issue to determine the AFs content and the quality of food. To comply with AFs standards in international trade improves the quality of national production and increases consumption of safe products in terms of AFs $[13,14]$.

According to the Turkish Food Codex [15, 16], the maximum values of AFB1 and total AFs are 8 and $15 \mu \mathrm{g} \mathrm{kg}^{-1}$ respectively for nuts, peanuts, pistachios, almonds and hard shell fruits (before processing) and are 5 and $10 \mu \mathrm{g} \mathrm{kg}^{-1}$ respectively for corn, black pepper and red pepper.

45 samples were used in experimental study and 90 measurements were carried out. According to the experimental results, amounts of AFB1 and total AFs is found to be below the maximum values of the Turkish Food Codex in $71.1 \%$ of the samples and are also found to be above them in 8 pieces of redpepper samples.

The maximum amount of AFB1 designed for foods in European countries and The United States is $5 \mu \mathrm{g} \mathrm{kg}^{-1}$ on all foods in countries such as the Netherlands, Belgium, Spain, Ireland, Greece, Denmark and is also $2 \mu \mathrm{g} \mathrm{kg}^{-1}$ in Germany. The maximum amount of total AFs $5 \mu \mathrm{g} \mathrm{kg}^{-1}$ on all foods in countries such as the Norway, Austria, Switzerland and Belgium is $4 \mu \mathrm{g} \mathrm{kg}^{-1}$ in Germany and is also $20 \mu \mathrm{g} \mathrm{kg}^{-1}$ in United States. According to the data given above, the maximum amount of AFB1 and total AFs is found to be below limit values in all samples excepted pepper [17]. 


\section{Conclusion}

This study was designed to detect presence and levels of AFs in dried apricots, raisins, dried figs, nuts, peanuts, almonds, corn, redpepper, blackpepper, bread and moldy cheese for human consumption in Karaman/Turkey. AFs were present $75 \%$ in dried apricots $(6 / 8), 100 \%$ in raisins $(8 / 8), 100 \%$ in dried figs $(8 / 8), 75 \%$ in nuts $(6 / 8), 50 \%$ in peanuts $(4 / 8), 50 \%$ in almonds $(4 / 8), 100 \%$ in corn $(8 / 8)$, $100 \%$ in black pepper $(8 / 8), 100 \%$ in red pepper $(8 / 8), 78.5 \%$ in bread 11/14), $75 \%$ in moldy cheese(3/4), at total AFs levels ranging. Eight red pepper samples were above the European maximum tolerable limit (MTL) of $8 \mu \mathrm{g} \mathrm{kg}^{-1}$ for AFB1, while total AFs concentration exceeded the MTL of $10 \mu \mathrm{g} \mathrm{kg}^{-1}$ in eight red pepper samples. The amount of aflatoxins in other samples is found to be below the values of Europen MLT [18, 19, 20].

The data reported in this survey could be used to carry out a preliminary risk assessment on AFs through red pepper consumption. Several codes of practice have been developed by Codex Alimentarius for the prevention and reduction of AFs in red pepper and other foods. The producers and processors should be considered the general principles given in the Code, taking into account Good Agricultural Practices (GAP), followed by the implementation of Good Manufacturing Practices (GMP) and Good Storage Practices (GMP) during the handling, processing, storage and distribution of red pepper for human consumption.

\section{Acknowledgements}

The authors thank to the Scientific Research Project Commission of Karamanoglu Mehmetbey University for financial support (BAP-Grant number 02-L-11).

\section{References}

[1] Sweeney, M. J., Dobson, A. D. W., (1998). International Journal of Food Microbiology, 43:141-158.

[2] European Food Safety Authority (EFSA), (2004). Opinion on the scientific panel on contaminants in the food chain on a request from the commission related to aflatoxin $\mathrm{B} 1$ as undesirable substance in animal feed. The EFSA Journal, 39: $1-27$.

[3] Eaton, D. L., Gallagher, E. P., (1994). Annual Review of Pharmacology and Toxicology 34: 135-172.

[4] International Agency for Research on Cancer (IARC), (1993). Some naturally occurring substances, food items and constituents, heterocyclic aromatic amines and mycotoxins (Vol. 56). Lyon France: World Health Organization.
[5] International Agency for Research on Cancer (IARC), (2002). Some traditional herbal medicines, some mycotoxins, naphthalene and styrene IARC monographs on the evaluation of carcinogenic risks to humans (Vol. 82). Lyon France.

[6] Ariño, A., Herrera, M., Estopañan, G., Rota, M. C., Carramiñana, J. J., Juan, T., (2009). Food Control, 20:811814.

[7] FAO (Food and Agricultural Organization of the United Nations), (2011). FAO statistical databases and data sets. http://www.faostat.fao.org/.

[8] European Commission, (2006b). Commission regulation (EC) No: 401/2006 of 23 February 2006 laying down the methods of sampling and analysis for the official control of the levels of mycotoxins in foodstuffs. Official Journal of the European Union, L70: 12-34.

[9] European Commission, (2010). Commission Regulation (EU) No: 165/2010 of 26 February 2006 amending Regulation (EC) No: 1881/2006 setting maximum levels for certain contaminants in foodstuffs as regards aflatoxins. Official Journal of the European Union, L50, 8-12.

[10] Truckess, M. W., Stack, M. E., Nesheim, S., Page, S. W., Albert, R. H., Hansen, T. J., (1991). Journal of the Association of the Official Analytical Chemistry, 74: 81-88.

[11] EURACHEM, (1998). The fitness for purpose of analytical methods. A laboratory guideto method validation and related topics. Middlesex, TW11 0LY, United Kingdom: EURACHEM Working Group.

[12] Hepsag, F., Golge, O., Kabak, B., (2014). Food Control, 38:75-81.

[13] Dreher, M. L., (2012). Nutrition Reviews, 70:234-240.

[14] Ulca, P., Evcimen, M. K., Senyuva, H. Z., (2010). Food Additives and Contaminants, Part B 3: 120-125.

[15] TUIK (Turkish Statistical Institute), (2011). The summary of agricultural statistics. http://tuik.gov.tr.

[16] Set, E., Erkmen, O., (2010). Food and Chemical Toxicology, 48:2532-2537.

[17] Codex Alimentarius Commission, (2002). Discussion paper on aflatoxins in pistachios. CX/FAC $02 / 22$, Joint FAO/WHO Food Standards Programme, Rotterdam, The Netherlands.

[18] Basaran, P., Ozcan, M., (2009). Journal of Food Safety, 29:95105.

[19] Gurses, M., (2006). International Journal of Food Properties, 92: 395-399.

[20] Kabak, B., Var, I., Dobson, A. D. W., (2006). Reviews in Food Science and Nutrition, 46:593-619. 